\title{
Bidirectional priming in infants
}

\author{
RACHEL BARR, AURORA VIEIRA, and CAROLYN ROVEE-COLLIER \\ Rutgers University, Piscataway, New Jersey
}

\begin{abstract}
In associative priming, the direct activation of one concept indirectly activates others that are associated with it, depending on the directionality of the association. We asked whether associative priming in preverbal infants is bidirectional. Infants associated a puppet imitation task with an operant train task by watching an adult model target actions on the puppet in the incidental context of the train. Later, priming of the forgotten memory of the train task reactivated the infants' memory of the puppet task (Experiment 1), and priming of the infants' forgotten memory of the puppet task reactivated their memory of the train task (Experiment 2). The finding that associative priming was bidirectional offers new insights into the nature of the mnemonic networks formed early in infancy. Additionally, the fact that the present association was formed rapidly and incidentally suggests that a fast mapping, general learning mechanism, like that posited to mediate word-object learning, was responsible for its encoding.
\end{abstract}

According to Estes (1976), new information is encoded and stored along with the context within which it occurs. If the new information matches information that has already been encoded and is stored at a higher level, an associative hierarchy is automatically formed. When the original encoding situation is either partially or fully reinstated, the memory of the original event is retrieved by the activation of the hierarchical associative network. Moreover, if the memories of two events are stored in the same associative hierarchy, the reactivation of one memory also reactivates the other (see also Bourne, Dominowski, \& Loftus, 1979; Bower, 1998; Collins \& Quillian, 1969).

An essential mechanism by which such associated memories are retrieved is associativepriming (McNamara, 1992). Priming refers to the facilitative effect of the prior presentation of an item or event on retention (Tulving \& Schacter, 1990). Lexical decisions about words (e.g., black) are faster, for example, if they are preceded by an associated word (e.g., white) than by an unrelated word (e.g., bread) (Warren, 1977). Priming is considered to be an automatic, perceptual identification process that implicitly activates a preexisting memory representation after a single brief presentation (Musen \& Treisman, 1990; Shimamura, 1986). In the animal and human infant literature, priming is called reactivation (Naito \& Komatsu, 1993; Nelson, 1995; Rovee-Collier, 1997; Rovee-Collier, Hayne, \& Colombo, 2001; Spear, 1973; Spear \& Parsons, 1976). As in studies with adults (e.g., Graf \& Mandler, 1984; Shimamura, 1986), the memory prime (or reactivation stimulus) is a fractional component of the original event and is pre-

This research was supported by Grants MH32307 and MH00902 from the National Institute of Mental Health to the third author. Correspondence should be addressed to C. Rovee-Collier, Department of Psychology, Rutgers University, 152 Frelinghuysen Rd., Piscataway, NJ 08854-8020(e-mail: rovee@ rci.rutgers.edu).

-Accepted by previous editorial team sented prior to the retention test, presumably increasing the accessibility of its memory representation (Spear, 1973; Spear \& Parsons, 1976). As a result, priming produces excellent retention at a time when subjects cannot recognize the prime (Tulving \& Pearlstone, 1966; Tulving, Schacter, \& Stark, 1982; for a review, see Rovee-Collier, 1997). Also, for both infants and adults, primes are effective only if they match the original encoding conditions fairly veridically (Ratcliff \& McKoon, 1988; Rovee-Collier, 1997; Tulving, 1983).

In the initial study of reactivation with human infants, 3-month-olds learned to move a crib mobile by kicking, forgot the task, and then were briefly exposed to the moving mobile as the memory prime either 2 or 4 weeks later (Rovee-Collier, Sullivan, Enright, Lucas, \& Fagen, 1980). Irrespective of the delay, infants exhibited excellent retention during the ensuing test, kicking at the same rate as they had kicked at the end of training weeks earlier. In contrast, forgetting and reactivation control groups exhibited no evidence of retention whatsoever. An identical result was obtained with 6-month-olds in the same task (Hill, Borovsky, \& Rovee-Collier, 1988), with 6-to 18-month-olds in a task in which lever-pressing moved a miniature train around a circular track (Hartshorn \& Rovee-Collier, 1997; Hildreth \& Rovee-Collier, 1999, 2000; Sweeney \& Rovee-Collier, 2000), and with 14- to 18-month-olds engaged in multiple activities in a laboratory setting (Sheffield \& Hudson, 1994).

Of particular interest for the present study is the consistent finding that infants' forgotten memory of one event is reactivated when their forgotten memory of a second, associated event is primed (Greco, Hayne, \& Rovee-Collier, 1990; Rovee-Collier, Greco-Vigorito, \& Hayne, 1993; Sheffield \& Hudson, 1994; Timmons, 1994). Timmons, for example, trained 6-month-old infants to move a mobile by foot kicking and then to turn on a music box by arm waving, or vice versa (mobile-arm wave, music box-footkick). Three weeks later, when the infants had forgotten both cue- 
response pairs, they were exposed to the music box as a memory prime and were subsequently tested with the mobile. Surprisingly, infants produced the mobile-appropriate response and no other. In other words, the reactivation of their memory of the music box task must have indirectly reactivated their memory of the mobile task, enabling them to perform the mobile-appropriate response during the test. This occurred regardless of the order in which the infants had learned the two tasks. Apparently, these two tasks had originally been associated by virtue of their being acquired in the same, highly distinctive context (Hayne, Greco-Vigorito, \& Rovee-Collier, 1993).

In a similar study, toddlers visited a laboratory playroom where they engaged in six different multistep activities at different stations (Sheffield \& Hudson, 1994). After they had forgotten the event, the toddlers returned to the laboratory and saw the experimenter repeat three of the original six activities (i.e., the memory prime). During testing the next day, the toddlers reproduced significantly more of the activities that they had not seen during priming than did the toddlers in the appropriate control groups. Apparently, the prime had directly reactivated the toddlers' memories of the three primed activities and had indirectly reactivated their memories of the remaining three. As before, the independentmemories of the different activities had undoubtedly been associated by virtue of their occurring in the same context.

Recently, Barr, Vieira, and Rovee-Collier (2001) reported that 6-month-olds' retention of an imitation task was protracted from 1 day (Barr, Dowden, \& Hayne, 1996) to 2 weeks when it was associated with an operant task that infants typically remember for 2 weeks (Hartshorn \& Rovee-Collier, 1997). The original association between the two tasks was formed when infants watched an adult model a series of target actions on a hand puppet (the imitation task) in the incidental context of a miniature train that the infants had learned they could move by leverpressing (the operant task). Although the infants imitated the target actions 2 weeks later, they did so only if their memory of the train task was tested first. In other words, retrieval of the longer lived memory of the train task was a prerequisite for retrieval of the shorter lived memory of the puppet imitation task. This result suggests that the association between the two tasks was unidirectional. This same result was found, however, even when infants originally saw the target actions modeled before they had ever learned the train task in the first place. Regardless of which task was acquired first, the infants formed an association between the puppet and train tasks as long as the target actions were modeled on the puppet in the visual context of the train. The latter observation raised the possibility that very young infants might be capable of forming bidirectional associations (Barr et al., 2001).

In the present study, therefore, we asked whether priming of each memory with the cue from the other would reactivate them both. To answer this, we used a reactivation paradigm that was functionally identical to priming procedures that have been used in studies with adults (Rovee-
Collier, 1997; Rovee-Collieret al., 2001) and arranged the experimental conditions so that infants would associate the puppet imitation task with the operant train task. Then, 3 weeks later when the infants had forgotten both tasks (Barr et al., 2001), we primed the forgotten memory of each task with the focal cue from the other task (an associative priming paradigm). Only if the association between the memories were bidirectional, would the cue from one task prime the other, restoring it once more to an accessible state. If the association between the two tasks were only unidirectional, however, the train should prime the memory of the puppet task, but the puppet should not prime the memory of the train task.

\section{EXPERIMENT 1 \\ Can the Train Prime the Memory of the Puppet Imitation Task?}

Although the puppet imitation task has been studied over the age range of 6 to 24 months (for review, see Barr \& Hayne, 2000), a priming procedure has been used in this task only once before, with 18-month-olds. We were unsure, therefore, whether the puppet memory of 6-month-olds could be primed at all. In contrast, a priming procedure has been used extensively in past studies with 6-montholds to reactivate the memory of the operant train task, and its parameters are well established (Hartshorn \& RoveeCollier, 1997; Hildreth \& Rovee-Collier, 1999, 2000). For this reason, we began by asking whether the direct priming of the forgotten train memory would prime the associated puppet memory.

\section{Method}

Participants. The sample consisted of 24 (12 boys, 12 girls) fullterm, 6-month-old infants who were recruited from published birth announcements in local papers. They were African American $(n=1)$, Asian $(n=3)$, and Caucasian $(n=20)$ and ranged in age from 179 to 206 days $(M=190.3$ days, $S D=7.0)$ on the first day of training. Their parents' mean educational level was 15.7 years $(S D=1.1)$, and their mean rank of socioeconomic status (Nakao \& Treas, 1992) was 68.3 $(S D=15.8)$. Testing was discontinued on additional infants for failing to meet the original learning criterion $(n=6)$, illness $(n=1)$, crying for 2 continuous minutes during any of the four sessions $(n=7)$, because of a scheduling conflict $(n=3)$, or refusing to touch the puppet $(n=3)$.

Apparatus. The operant apparatus consisted of an HO-scale (miniature) train in a wooden box $(58 \times 58 \times 35 \mathrm{~cm})$, three sides of which were enclosed by a colorful, patterned curtain. The front of the box was Plexiglas $(58 \times 35 \mathrm{~cm})$, and a Plexiglas lever $(30 \times$ $12.5 \mathrm{~cm}$ ) was mounted at its base. When depressed, the lever operated a microswitch that was connected to an interface box and an IBM Thinkpad-350 laptop computer. A Quick Basic computer program timed the experimental phases, delivered the reinforcement, and registered all microswitch operations in 10-sec bins. The train consisted of an engine and three brightly colored rail cars. At the outset of each session, the train was positioned immediately behind the front window on a circular track (47.5-cm diameter). Two train sets, counterbalanced within and across groups, were used. One set was green and had a yellow curtain with green squares. Its engine was black, and its rail cars were brown, silver, and purple. The other set was pink and had a red-and blue-striped curtain. Its engine was black, and its rail cars were brown, green, and red. Both sets had nu- 
merous small toys around the track and a 40-W white light bulb in the upper right corner that continuously illuminated the interior during experimental phases.

In the imitation task, we used one of two hand puppets, a pastel pink rabbit and a pale gray mouse, that were constructed for these experiments and were not commercially available. Both puppets were $30 \mathrm{~cm}$ in height and were made of soft, acrylic fur. A removable felt mitten $(8 \times 9 \mathrm{~cm})$ in a matching color covered each puppet's right hand. A large jingle bell was secured to the inside of the mitten during the demonstration but was removed during testing. The puppets were counterbalanced within groups.

Training procedures. All infants were trained and tested in their own homes at a time of day that their caregivers thought they would be playful. This time varied from infant to infant but remained fairly constant for all sessions with a given infant.

Operant train task. The train was set up on a table in the infant's home, and the infant sat on his/her caregiver's lap in front of it with the lever being chest high. The infants received two identical 8-min training sessions on consecutive days. The sessions began with a 1-min nonreinforcement period when the lever was deactivated. In Session 1, this constituted the baseline phase, during which the infants' unlearned rate of lever-pressing was recorded. Next followed a 6min reinforcement period (acquisition), during which the lever was active, and each lever press moved the train for $2 \mathrm{sec}$ (see Figure 1). Presses that occurred while the train was in motion were registered by the computer but had no effect on the delivery of reinforcement. The sessions ended with a 1-min nonreinforcement phase in which the lever was again deactivated so that lever presses did not move the train. In Session 2, this phase served as an immediate retention test, during which the infants' final level of learning and retention after zero delay was measured. To be eligible for retention testing, an infant was required to respond at least 1.5 times above his or her baseline rate in any 2 of any 3 consecutive minutes of either acquisition period (the learning criterion).

Puppet imitation task. Immediately following Session 2 of the train task, the caregiver, with the infant still on her lap, rotated her chair to the side so that the train remained visible on the left or the right of the infant (see Figure 2). The experimenter then knelt, placed the puppet over her right hand, and positioned it at the infant's eye level-approximately $80 \mathrm{~cm}$ from the infant's chest. The time between the end of the train session and the beginning of the puppet demonstration was less than a minute. The experimenter removed the mitten from the puppet's right hand, shook it three times to ring the bell that was attached inside, and replaced the mitten. This sequence was repeated five times for a total of approximately $60 \mathrm{sec}$. Immediately after the demonstration, the infants were allowed to imitate the target actions three times. The mean duration of the immediate imitation phase was $174 \mathrm{sec}(S E=30)$.

Reactivation (priming) procedure. The infants were randomly assigned to a train reactivation group, train reactivation-nonmoving

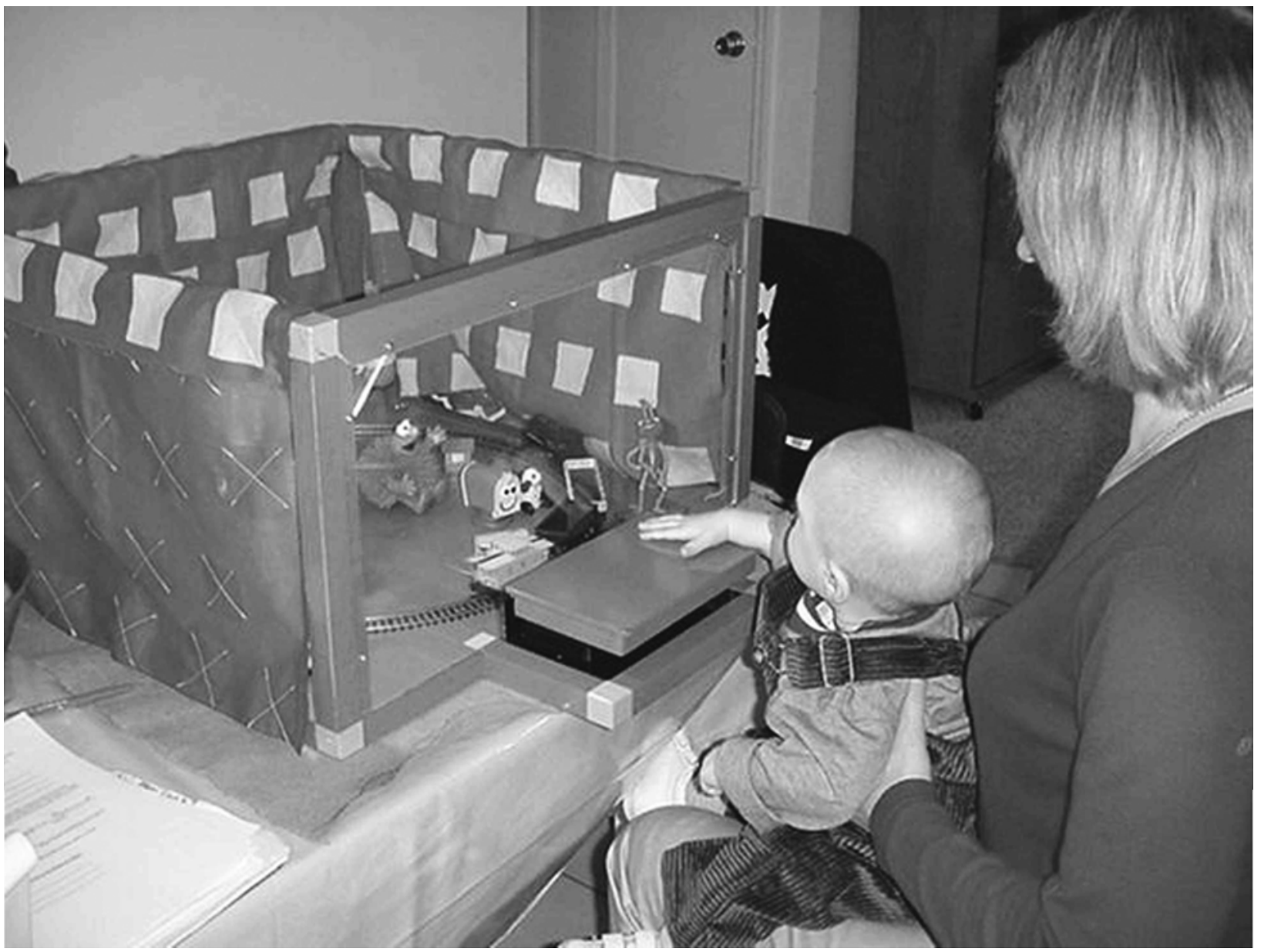

Figure 1. A 6-month-old pressing the lever to operate the toy train. Each discrete response moved the train for 2 sec. 


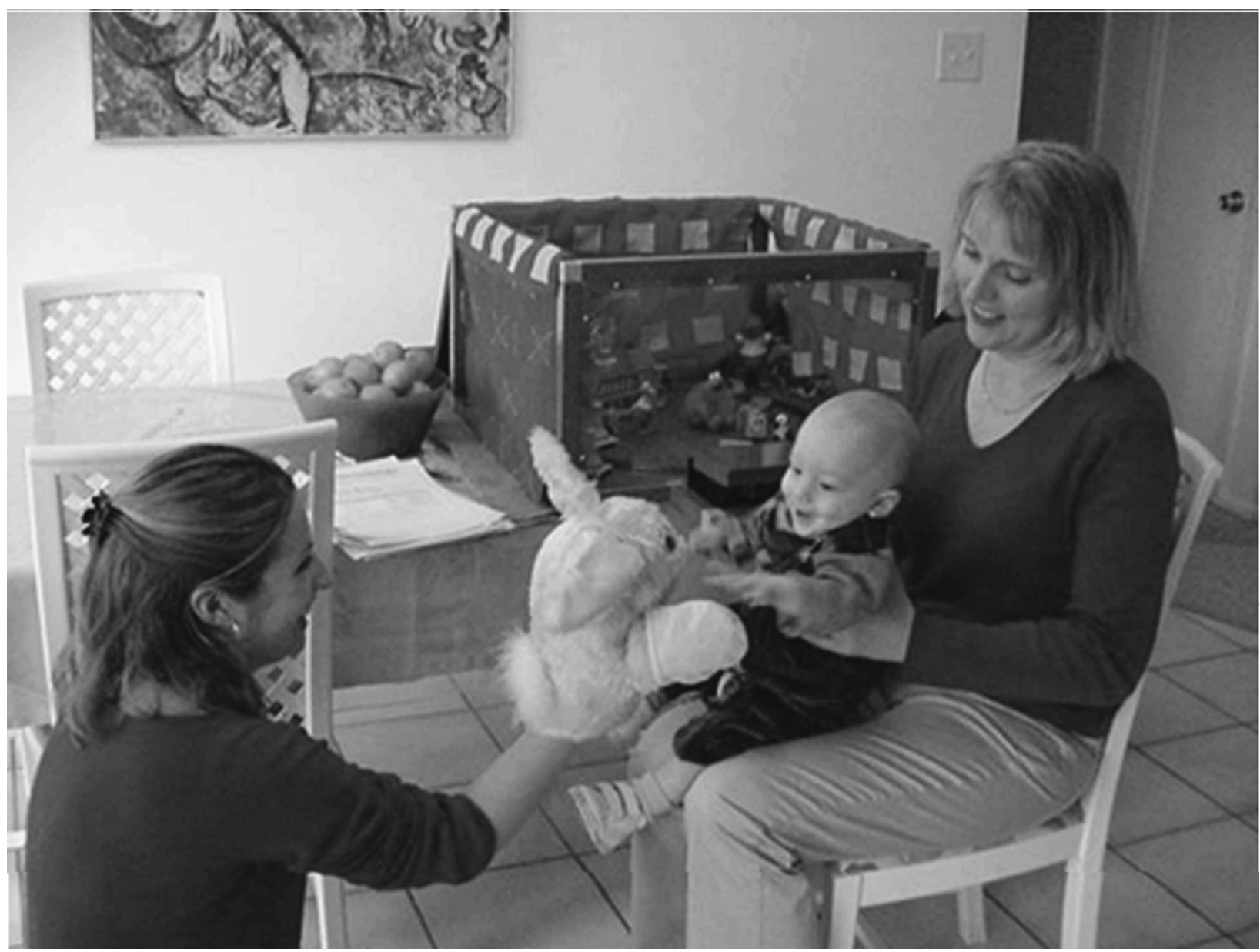

Figure 2. The experimental arrangement used with 6-month-old infants in the puppet imitation task. The target actions were modeled on the puppet immediately after the end of training on the operant task; note that the train set is still in view. Imitation was tested with the puppet in this same context.

group, an untrained reactivation control group, and a forgetting control group. All but the forgetting control group received a reactivation treatment 20 days after the end of Session 2, 1 day prior to the longterm retention test. During the reactivation treatment, all the infants were passively exposed to the moving train for $2 \mathrm{~min}$ while the lever was deactivated. For the two experimental groups, the frequency and temporal pattern of train movement was computer programmed to reproduce a given infant's responding during the final 2 min of acquisition in Session 2. For the untrained reactivation control group, the frequency and temporal pattern of train movement was yoked to that of an infant in the train reactivation group. At the end of the second minute, the caregiver removed the infant from in front of the train set, and the reactivation treatment was over.

Retention test procedures. Twenty-four hours after the reactivation treatment, the infants either were tested for 2 min with the nonmoving train (the train reactivation-nonmoving group) or were merely exposed for 2 min to the moving train as a precue ${ }^{1}$ (the train reactivation group and the reactivation control group). The precue was procedurally identical to the reactivation treatment that the infants had received $24 \mathrm{~h}$ earlier. Immediately after the 2-min test or precue, all the infants received a 2-min imitation test with the puppet. During the imitation test, the bell was removed from inside the puppet's mitten. After the imitation test, the train reactivation group received a 2-min retention test with the nonmoving train, and both experi- mental groups received a 6-min reacquisition phase with the train. The latter phase was introduced in order to ensure that the infants who had performed poorly on the train test were not sick, fatigued, or otherwise unmotivated on that particular day. None were-all responded appropriately when the contingency was reintroduced.

Two standard control groups were included in the design. First, the reactivation control group received the train reactivation treatment but had not been operantly trained and had not seen the target actions demonstrated. This group was included in order to ensure that precuing with the moving train immediately before the puppet imitation test did not behaviorally arouse infants to the point that they would spontaneously remove the mitten. This group received only the reactivation treatment, the precue, and the puppet imitation test. Second, the forgetting control group originally learned the train task and saw the target actions demonstrated on the puppet but received neither a reactivation treatment nor a precue prior to the long-term retention tests on both tasks. This group was included in order to ensure that both the train task and the puppet demonstration had been forgotten at the time of testing. This group received the 2-min test with the nonmoving train, a standard 6-min reacquisition phase in which lever-pressing moved the train, and then a 2-min imitation test with the puppet.

Puppet imitation test. During the puppet imitation test, each infant sat on his/her caregiver's lap with the train in the infant's visual field. The experimenter knelt in front of the infant and held the hand pup- 
pet approximately $30 \mathrm{~cm}$ from the infant, within the infant's reach. Subsequently, a trained observer scored each videotaped test session for $120 \mathrm{sec}$ from the time that the infant first touched the puppet. A second trained observer, blind to the infants' group assignments, scored $100 \%$ of the test sessions. An imitation score was calculated for each infant by summing the number of target behaviors (removal of the mitten, shaking the mitten, or an attempt to put the mitten back on the puppet) that were produced during the test (range 0-3). Interobserver reliability was $98.6 \%($ Kappa $=.96)$.

Operant train task. After they had completed the puppet task, the infants in the train reactivation group participated in the 2-min longterm retention test with the nonmoving train followed by a 6 -min reacquisition phase. During the 2-min long-term retention test with the train, the infant again sat on the caregiver's lap, and the lever was deactivated. Immediately after the long-term test, reinforcement was reintroduced in order to ensure that the infants who did not respond during the test were not ill or unmotivated on that particular day. Again, none were.

\section{Results and Discussion}

Puppet imitation task. The mean imitation scores of the infants in the train reactivation, train reactivationnonmoving, untrained reactivation control, and forgetting control groups were subjected to a one-way analysis of variance (ANOVA). This analysis indicated that the groups differed significantly $[F(3,20)=4.21, p<.05]$ (see Figure 3 , left panel).
Directional Dunnett's $t$ tests $(p<.05$ across multiple comparisons with the untrained reactivation control) revealed that the mean imitation scores of the train reactivation group and the train reactivation-nonmoving group significantly exceeded the mean imitation score of the untrained reactivation control group $[t(20)=2.98, p<.05$ and $t(20)=$ $2.98, p<.05$, respectively], but that the imitation performance of the forgetting control group did not $[t(20)<$ $1.27, \mathrm{n} . \mathrm{s}$.]. The fact that the untrained reactivation control group did not spontaneously produce the target behavior confirmed that the significant imitation performance of two experimental groups was due to their memory of the prior event. Thus, although the infants had last seen the target actions demonstrated on the puppet 3 weeks earlier and had subsequently forgotten this event, reactivating their train memory indirectly reactivated their memory of the puppet imitation task via the association that had been formed between these tasks. The significant imitation performance of the train reactivation-nonmoving group further demonstrated that, once the train memory had been reactivated $24 \mathrm{~h}$ earlier, retrieval of the train memory immediately prior to the puppet imitation test was all that was necessary to retrieve the puppet memory at the time of testing; their seeing the train actually move was not. The forgetting control group confirmed that, without a reacti-

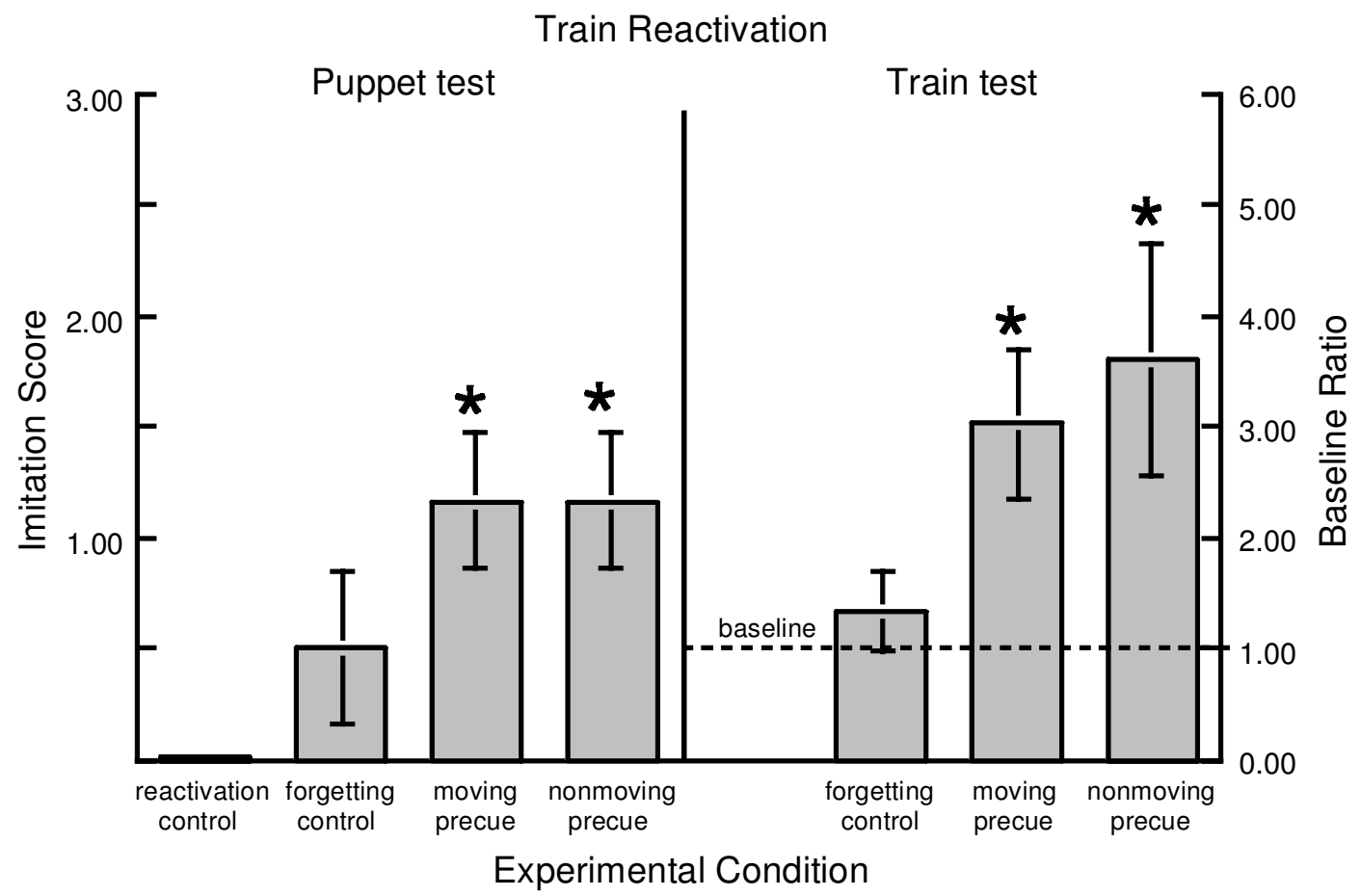

Figure 3. Left panel: The mean imitation scores $(+1 S E)$ of 6-month-olds whose forgotten puppet imitation memory was indirectly reactivated by exposure to the moving train and then was precued with either the moving train or the nonmoving train (Experiment 1). Right panel: The mean baseline ratios $(+1 S E)$ of 6-month-olds whose forgotten operant train memory was directly reactivated, precued, and tested with the train either before (nonmoving) or after (moving) the puppet test (Experiment 1). The dotted line (baseline) indicates the infants' unlearned rate of lever-pressing. In both panels, asterisks indicate that a group exhibited significant retention (i.e., performed significantly above baseline). 
vation treatment, the puppet task was forgotten 3 weeks after the demonstration.

Operant train task. One-way ANOVAs indicated that the mean response rates of the train reactivation group, the train reactivation-nonmoving group, and the forgetting control group did not differ during either the baseline phase $[F(2,15)<1]$ or the immediate retention test $[F(2,15)<1]$. These results eliminated group differences in baseline activity and the final level of learning as the basis for any subsequent group differences in retention.

After the infants were tested with the puppet, 5 infants in the train reactivation group received a long-term retention test with the train in order to ensure that their train memory had indeed been reactivated. Retention is measured prior to reacquisition during a nonreinforcement phase (i.e., what infants bring into the session) rather than during reacquisition (savings).

Retention was assessed by using an individual measure of relative response, the baseline ratio, which we have used in all previous operant studies of infant memory (RoveeCollier, 1996). The long-term retention test with the train is a yes/no recognition test. If the infants recognize the train at the time of testing, they say "yes" by responding above baseline; otherwise, they say "no" by responding at baseline. Because the baseline ratio is an all-or-none measure of recognition (Rovee-Collier, 1996), comparison between the baseline ratios of different groups is not meaningful. The baseline ratio is calculated by dividing each infant's response rate during the long-term retention test by that of the same infant's response rate during the baseline phase. A mean baseline ratio of 1.00 indicates that a group responded at operant level during the long-term retention test (i.e., no retention); a mean baseline ratio significantly greater than 1.00 indicates significant retention. The use of individually based measures of relative response is important because group means based on absolute levels of response before and after a retention interval are not sensitive to individual variability in the base rate of the target response, and group changes in absolute responding over the retention interval do not necessarily reflect individual changes. The use of individually based ratios eliminates these problems. (For extended discussion of measurement problems, see Rovee-Collier, 1996.)

Prior to performing all analyses in this experiment and in Experiment 2, we tested the baseline ratios in each group for outliers (Tukey, 1977, pp. 43-44). Any ratio falling above the value of the 90 th percentile (the outer fence) was replaced with the next highest baseline ratio in that group, and one degree of freedom was subtracted.

A directional $t$ test comparing the mean baseline ratio of the train reactivation group with a theoretical population baseline ratio of 1.00 (no retention) confirmed that the group exhibited significant retention $24 \mathrm{~h}$ after reactivation treatment. The mean baseline ratio of this group was significantly greater than $1.00[t(3)=3.00, p<.05]$ (see Figure 3, right panel). Recall that the long-term retention test had served as the precue for the reactivation-nonmoving group. The mean baseline ratio of this group during its long-term test was also significantly greater than 1.00 $[t(5)=2.47, p<.03]$, confirming that the infants' memory had also been successfully reactivated $24 \mathrm{~h}$ earlier. The forgetting control group was tested first with the train and then with the puppet. As expected, this group exhibited no retention during the long-term retention test with the train. The mean baseline ratio for this group was not significantly greater than $1.00[t(4)<1]$ (see Figure 3 , right panel).

Taken together, these results demonstrate that the infants formed an association between the train and the puppet tasks and that by directly priming one member of the association, the other member was indirectly primed as well. If the memory of the train task was not retrieved at the time of testing, however, the reactivated memory of the puppet imitation task was not retrieved either-just as had occurred when retention of the newly acquired memories of the associated train and puppet tasks had been tested (Barr et al., 2001).

\section{EXPERIMENT 2 \\ Can the Puppet Prime the Memory of the Train Task?}

In Experiment 1, we determined that reactivation of the operant train memory could indirectly reactivate the puppet imitation memory if the two tasks had previously been associated, but retrieval of the train memory was a prerequisite for retrieval of the puppet memory. If the two memories were associated in a common mnemonic network, however, direct reactivation of the puppet memory should indirectly reactivate the train memory as well (i.e., backward priming).

In a study of backward priming with adults, Arcediano, Escobar, and Miller (2000) trained subjects to hold a space bar down when they expected a presentation of the unconditioned stimulus (US). Using a sensory preconditioning procedure, they exposed subjects to two stimuli, one after the other (the conditioned stimuli, X and A), in Phase 1. In Phase 2, they presented subjects with the US followed by stimulus A. In Phase 3 (the test), they presented stimulus $\mathrm{X}$ and then stimulus A but omitted the US. The experimental question was whether subjects would expect the US to occur before conditioned stimulus A or afterward. The subjects pressed the space bar when presented with stimulus $\mathrm{X}$, before stimulus A was presented, indicating that they had formed a backward association when the US had preceded stimulus A in Phase 2.

Other evidence obtained from adults has demonstrated that priming is determined by the nature of the association between the components. In two experiments, Zeelenberg, Shiffrin, and Raaijmakers (1999) used a free-recall task to examine whether a priming effect would be found for backward associations. As determined by word frequency norms, the target words on their study list had either unidirectional associations (e.g., bone cues $d o g$, but $d o g$ does 
not cue bone) or bidirectional associations (i.e., sand cues beach, and beach cues sand). They found that priming occurred only when there was a bidirectional (backward) association between the two words. If there was only a unidirectional association, there was no priming effect. Zeelenberg et al. interpreted this result in terms of the strengthening of bidirectional target-cue associations during the initial study period.

Because whether the association between two concepts is bidirectional or unidirectional determines whether or not they will prime one another, in Experiment 2, we asked whether the puppet could prime the associated train memory. If so, we would take this as being diagnostic of the bidirectionality of the association between the tasks.

\section{Method}

Participants. The participants were 12 (4 male, 8 female) 6 month-old infants who were recruited from published birth announcements and by word of mouth. The participants were Asian $(n=1)$ and Caucasian $(n=11)$ and ranged in age from 179 to 198 days $(M=$ 188.9 days, $S D=7.8$ ) on the first day of training. Their parents' mean educational level was 15.7 years $(S D=1.2)$, and their mean rank of socioeconomic status (Nakao \& Treas, 1992) was $68.9(S D=$ 18.7). (The latter statistic was based on information from $83 \%$ of the sample.) Testing was discontinued on additional infants for failing to meet the original learning criterion $(n=6)$, crying for 2 continuous minutes during any of the four sessions $(n=1)$, refusing to touch the puppet $(n=2)$, or because of equipment failure $(n=2)$.

Apparatus and Procedure. The apparatus, training procedure, and test procedure were the same as those used in Experiment 1. The infants were randomly assigned to one of two groups as they became available for study. The mean duration of the immediate imitation phase (i.e., how long the infants took to imitate the target actions three times after the demonstration) was $248 \mathrm{sec}(S E=64)$.

The puppet reactivation group received a reactivation treatment with the puppet 20 days after the end of training. As in Experiment 1, the reactivation treatment was a fractional component of the original training event. This time, however, the memory prime was a demonstration of the target actions on the puppet three times for a total of $30 \mathrm{sec}$. Barr et al. (1996) had previously found that 6-month-olds cannot imitate the target actions $24 \mathrm{~h}$ later if they see them demonstrated for only $30 \mathrm{sec}$ and are not allowed to imitate immediately afterward. During the puppet reactivation treatment, the train set was on a table to the infant's side, as it had been originally (see Figure 2).

The puppet-only control group was never exposed to the train task but was trained and reactivated in the same way as the puppet reactivation group. This group was included to control for the behaviorally arousing effects of the puppet reactivation treatments. In addition, this group was included in order to assess whether the puppet memory alone would be reactivated after a 3 -week delay in the absence of train learning. (A forgetting control group was not tested in Experiment 2 because it had been tested in the preceding experiment.)

Both groups were precued $24 \mathrm{~h}$ after the reactivation treatment, immediately before the long-term retention test with the train. ${ }^{2}$ This time, the jingle bell was secured to the back of the puppet, instead of inside the mitten. No target actions were demonstrated. Instead, the experimenter held the puppet in front of the infant and merely shook it three times, ringing the bell, for a total of $30 \mathrm{sec}$.

Operant train test. Immediately after being precued with the puppet, the infants in the puppet reactivation group were tested with the train in the same manner as that in Experiment 1.

Puppet imitation test. After they were tested with the train, 5 infants in the puppet reactivation group received a long-term retention test with the puppet in order to ensure that the puppet memory had indeed been reactivated. After the puppet precue, all the infants in the puppet-only control group were tested with the puppet. Interobserver reliability was $100 \%(\mathrm{Kappa}=1.00)$.

\section{Results and Discussion}

Because only the puppet reactivation group learned the train task, we thought it important to ensure that its baseline and final level of learning were not atypical. Therefore, we performed separate one-way ANOVAs over the mean baseline and immediate retention test (IRT) response rates of the puppet reactivation group and the trained groups from the preceding experiment. These analyses indicated that the puppet reactivation group did not differ from the other groups during either the baseline phase $[F(3,20)=$ 1.24, n.s.] or the IRT $[F(3,20)<1]$. A directional $t$ test comparing the mean baseline ratio of the puppet reactivation group with a theoretical population baseline ratio of 1.00 (no retention) indicated that after exposure to the puppet prime, this group exhibited significant retention when subsequently tested with the train. The mean baseline ratio for this group was significantly greater than $1.00[t(4)=$ $2.87, p<.05]$ (see Figure 4, left panel). Thus, not only did exposure to the train reactivate the puppet imitation memory, but exposure to the puppet reactivated the operant train memory.

In order to ensure also that the puppet-only control group did not differ from the control groups in Experiment 1, we subjected its performance during the imitation test along with that of the reactivation and forgetting control groups from Experiment 1 to a one-way ANOVA. This analysis indicated that the mean imitation score of the puppet-only control group was not different from those of the other two control groups $[F(2,15)=1.34$, n.s. $]$. Not surprisingly, the puppet reactivation treatment also reactivated the puppet imitation memory. The mean imitation score of the puppet reactivation group was significantly higher than that of the puppet-only control group $[t(9)=2.45, p<.05]$ (see Figure 4 , right panel). The finding that the puppet-only control group did not exhibit retention of the puppet task after the reactivation treatment confirmed that our initially associating the train task with the demonstration of the target actions on the puppet was necessary for the puppet memory to be reactivated after a 3 -week delay. The finding that a fractional component of either member of the original association was able to prime the other confirmed that the association between the tasks was bidirectional.

These results are consistent with the results of Arcediano et al. (2000) and Zeelenberg et al. (1999). Whereas Zeelenberg et al. predicted a preexisting backward association by means of the word frequency norms that they had originally used to select words for their study lists, the Arcediano et al. study and the present one established the backward association by means of a manipulation within the context of the experiment. Finally, the present results add to the growing body of evidence that memories that have been forgotten can be reactivated by exposing indi- 


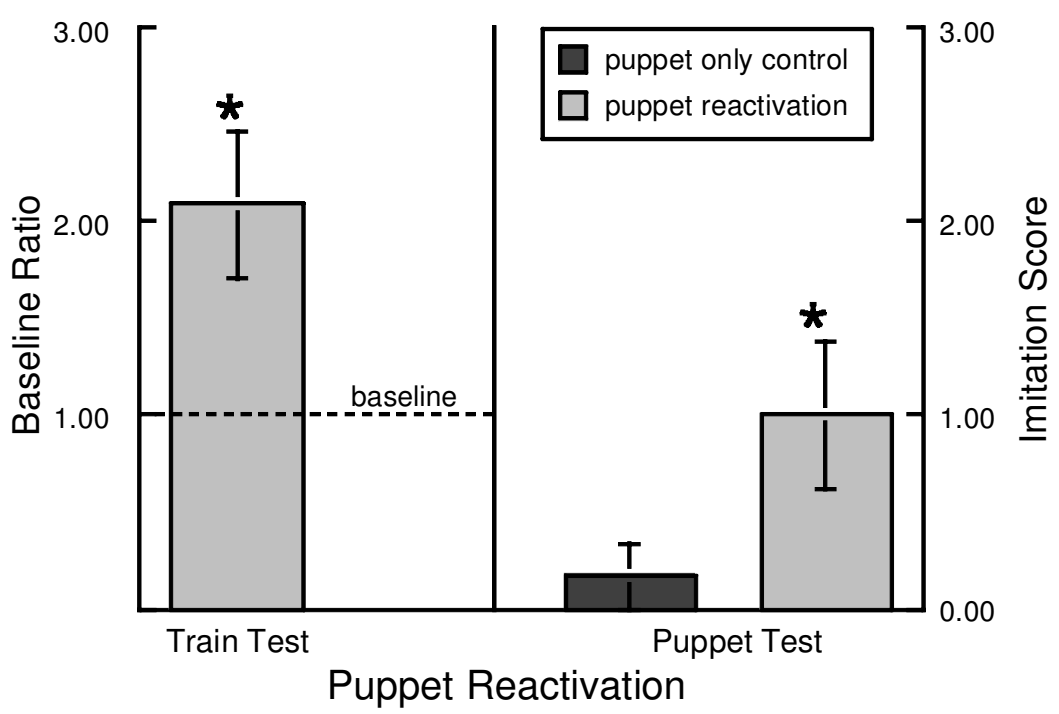

Figure 4. Left panel: The mean baseline ratio $(+1 S E)$ of 6 -month-olds whose memories were reactivated and precued with the puppet and who were tested with the train $24 \mathrm{~h}$ later (Experiment 2). The dotted line (baseline) indicates the infants' unlearned rate of lever-pressing. Right panel: The mean imitation score $(+1 S E)$ of 6 month-olds whose memories were reactivated and precued with the puppet and who were tested with the train and subsequently tested with the puppet (Experiment 2). In both panels, asterisks indicate that a group performed significantly above baseline.

viduals to appropriate memory primes. Here, the appropriate prime in each case included information that was only associated with the target memory.

These findings, however, raise the question of why it was necessary to precue the puppet task but not the train task. Recall that the initial strengths of the two memories were not equivalent. Whereas the puppet task was remembered for 1 day, the train task was remembered for 2 weeks. Yet, the reactivation treatment occurred 3 weeks after training at a point when the train memory had been forgotten for only 1 week, but the puppet memory had been forgotten for almost 3 weeks. The fact that the puppet task required a precue 1 day after priming but the train task did not, then, was a function of the relative strengths of the independent memory traces that were originally formed at the time of encoding.

\section{GENERAL DISCUSSION}

Bidirectionality of associations has important implications for memory retrieval. When an association between two events is bidirectional, the number of effective retrieval cues for each memory is doubled, thereby doubling the probability that on any given occasion the memory will be retrieved. Further, if the increase in the absolute number of memories in a network is described by a natural log function, the ability to bidirectionally encode these memories will dramatically expand the number of retrieval cues available to infants.

The present finding that the bidirectional association was formed so rapidly and effortlessly by very young infants is consistent with the claim that a general learning mechanism that links incidental events with one another was responsible for its acquisition and retention. This finding is reminiscent of fast mapping, which refers to the ability to map meaning, function, relations, and properties of words to the corresponding object after a few incidental exposures and then to retrieve that knowledge across long delays (Markson \& Bloom, 1997). Although fast mapping has been described as a device that is specialized for word learning, Bloom and Markson (2001) have argued that the mechanism responsible for rapid acquisition and retention of new word-object associations is not unique to word learning but is a general learning mechanism. The present data strongly suggest that such a mechanism (or fast mapping) is fully functional well in advance of the phase of receptive language in very young infants and long before the typical word production spurt between 18 and 24 months of age.

A fast mapping, bidirectional encoding mechanism would be particularly adaptive early in infancy, when memories are forgotten rapidly and the knowledge base is relatively lean. Furthermore, if fast mapping links not only two independent memories but also several activities that occur in succession, it would promote a veritable explosion in the formation of complex associative networks that could then be activated by any member of the network.

Whereas fast mapping may be the encoding mechanism for bidirectional associations, spreading activation is a potential retrieval mechanism. McNamara (1992) outlined three main assumptions of spreading activation. First, activation spreads through an interconnected network of memory traces. Second, when an item is retrieved from 
memory, its internal representation is activated. And third, the residual activation that is accumulated at memory traces facilitates the retrieval of related information. There has been considerable debate about whether spreading activation can account for backward priming. According to Collins and Loftus (1975; see also Loftus, 1973), information is stored in hierarchical concept nodes that share common properties. In addition, closely related concept nodes might share many links. By their account, activation spreads throughout the associative network - either forward or backward-depending on the extent to which other concept nodes are closely related to the node that was originally activated.Zeelenberg et al. (1999) argued that a unitary memory system such as ACT* (Anderson, 1983) cannot account for their data because it predicts priming regardless of the presence/absence of a backward association.

Finally, advocates of the compound-cue account (a competing account of associative priming) have argued that the strength of the association between the target and the prime is an important determinant of the subsequent priming effect and therefore can account for backward priming effects (Ratcliff \& McKoon, 1988). Whatever the preferred account, the present data reveal that an association between two relatively disparate events that are related only by virtue of their sharing a common incidental context can be both bidirectionally and indirectly primed. In our view, the notion of spreading activation as articulated by McNamara (1992) or residual priming (Bower, 1998) adequately accounts for this result.

\section{REFERENCES}

Anderson, J. R. (1983). The architecture of cognition. Cambridge, MA: Harvard University Press.

Arcediano, F., Escobar, M., \& Miller, R. R. (2000, March). Temporal coding and backward associations in humans. Paper presented at the meeting of the Eastern Psychological Association, Baltimore.

BARr, R, Dowden, A., \& Hayne, H. (1996). Developmental changes in deferred imitation by 6- to 24-month-old infants. Infant Behavior \& Development, 19, 159-170.

BARr, R, \& HAYNe, H. (2000). Age-related changes in imitation: Implications for memory development. In C. Rovee-Collier, L. P. Lipsitt, \& H. Hayne (Eds.), Progress in infancy research (Vol. 1, pp. 21-67). Mahwah, NJ: Erlbaum.

Barr, R., Vieira, A., \& Rovee-Collier,C. (2001). Mediated imitation at 6 months of age: Remembering by association. Journal of Experimental Child Psychology, 79, 229-252.

Bloom, P., \& MARKson, L. (2001). Are there principles that apply only to the acquisition of words? A reply to Waxman \& Booth. Cognition, 78, 89-90.

Bourne, L. E., Dominowski, R. L., \& Loftus, E. F. (1979). Cognitive processes. Englewood Cliffs, NJ: Prentice-Hall.

Bower, G. H. (1998). An associative theory of implicit and explicit memory. In M. A. Conway, S. E. Gathercole, \& C. Cornoldi(Eds.), Theories of memory (Vol. 2, pp. 25-60). Hove, U.K.: Psychology Press.

Collins, A. M., \& Lofrus, E. F. (1975). A spreading activation theory of semantic processing. Psychological Review, 82, 407-428.

Collins, A. M., \& Quillian, M. R. (1969). Retrieval time from semantic memory. Journal of Verbal Learning \& Verbal Behavior, 8, 240-247.

ESTES, W. K. (1976). Structural aspects of associative models for memory. In C. N. Cofer (Ed.), The structure of human memory (pp. 31-53). San Francisco: Freeman.

Graf, P., \& MANDler, G. (1984). Activation makes words more acces- sible, but not necessarily more retrievable. Journal of Verbal Learning \& Verbal Behavior, 23, 553-568.

Greco, C., Hay ne, H., \& Rovee-Collier,C. (1990). Roles of function, reminding, and variability in categorization by 3 -month-old infants. Journal of Experimental Child Psychology: Learning, Memory, \& Cognition, 16, 617-633.

Gulya, M., Rovee-Collier, C., Galluccio, L., \& Wilk, A. (1998). Memory processing of a serial list by young infants. Psychological Science, 9, 303-307.

Gulya, M., Sweeney, B., \& Rovee-Collier, C. (1999). Infants' memory processing of a serial list: List length effects. Journal of Experimental Child Psychology, 73, 72-91.

Hartshorn, K., \& Rovee-Collier, C. (1997). Infant learning and longterm memory at 6 months: A confirming analysis. Developmental Psychobiology, 30, 71-85.

Hayne, H., Greco-Vigorito, C., \& Rovee-Collier, C. (1993). Forming contextual categories in infancy. Cognitive Development, 8, 63-82.

Hildreth, K., \& Rovee-Collier, C. (1999). Decreases in the response latency to priming over the first year of life. Developmental Psychobiology, 35, 276-290.

Hildreth, K., \& Rovee-Collier, C. (2000, July). Developmental changes in forgetting of reactivated memories over the first year of life. Paper presented at the International Conference on Infant Studies, Brighton, U.K.

Hill, W. L., Borovsky, D., \& Rovee-Collier, C. (1988). Continuities in infant memory development. Developmental Psychobiology, 21, 43-62.

LofTus, E. F. (1973). Category dominance, instance dominance, and categorization time. Journal of Experimental Psychology, 97, 70-74.

MARKSON,L., \& BloOM, P. (1997). Evidence against a dedicated system for word learning in children. Nature, 385, 813-815.

McNamara, T. P. (1992). Priming and constraints it places on theories of memory and retrieval. Psychological Review, 99, 650-662.

Musen, G., \& Treisman, A. (1990). Implicit and explicit memory for visual patterns. Journal of Experimental Psychology: Learning, Memory, \& Cognition, 16, 127-137.

Naito, M., \& Komatsu, S. I. (1993). Processes involved in childhood development of implicit memory. In P. Graf \& M. E. J. Masson (Eds.), Context and learning (pp. 385-406). Hillsdale, NJ: Erlbaum.

NaKaO, K., \& Treas, J. (1992). The 1989 socioeconomic index of occupations: Construction from the 1989 occupational prestige scores (General Social Survey Methodological Reports No. 74). Chicago: NORC.

NELSON, C. (1995). The ontogeny of human memory: A cognitive neuroscience perspective. Developmental Psychology, 31, 723-738.

Ratcliff, R., \& McKoon, G. (1988). A retrieval theory of priming. Psychological Review, 95, 385-408.

Rovee-Collier, C. (1996). Measuring infant memory: A critical commentary. Developmental Review, 16, 301-310.

Rovee-Collier, C. (1997). Dissociations in infant memory: Rethinking the development of implicit and explicit memory. Psychological Review, 104, 467-498.

Rovee-Collier, C., Greco-Vigorito, C., \& Hayne, H. (1993). The time window hypothesis: Implications for categorization and memory modification. Infant Behavior \& Development, 16, 149-176.

Rovee-Collier, C., Hayne, H., \& Colombo, M. (2001). The development of implicit and explicit memory. Amsterdam: John Benjamins.

Rovee-Collier, C., Sullivan, M. W., Enright, M., Lucas, D., \& FAGEN, J. (1980). Reactivation of infant memory. Science, 208, 11591161.

Sheffield, E. G., \& Hudson, J. A. (1994). Reactivation of toddler's event memory. Memory, 2, 447-465.

Shimamura, A. P. (1986). Priming effects in amnesia: Evidence for dissociable memory function. Quarterly Journal of Experimental Psychology, 38A, 619-644.

Spear, N. E. (1973). Retrieval of memories in animals. Psychological Review, 80, 163-194.

Spear, N. E., \& Parsons, P. J. (1976). Analysis of a reactivation treatment: Ontogenetic determinants of alleviated forgetting. In D. L. Medin, W. A. Roberts, \& R. T. Davis (Eds.), Process of animalmemory (pp. 135165). Hillsdale, NJ: Erlbaum. 
Sweeney, B., \& Rovee-Collier, C. (2000, July). The relative persistence of a memory after reactivation and reinstatement at 6 months of age. Paper presented at the International Conference on Infant Studies, Brighton, U.K.

Timmons, C. R. (1994). Associative links between discrete memories in early infancy. Infant Behavior \& Development, 17, 431-445.

Tukey, J. W. (1977). Exploratory data analysis. Reading, MA: AddisonWesley.

Tulving, E. (1983). Elements of episodic memory. New York: Oxford University Press.

Tulving, E., \& Pearlstone, Z. (1966). Availability versus accessibility of information in memory for words. Journal of Verbal Learning \& Verbal Behavior, 5, 381-391.

Tulving, E., \& Schacter, D. L. (1990). Priming and human memory systems. Science, 247, 301-306.

Tulving, E., Schacter, D. L., \& Stark, H. A. (1982). Priming effects in word-fragment completion are independent of recognition memory. Journal of Experimental Psychology: Learning, Memory, \& Cognition, 8, 336-342.

WARren, R. E. (1977). Time and spread of activation in memory. Journal of Experimental Psychology: Human Learning \& Memory, 3, 458 466.

Zeelenberg, R, Shiffrin, R. M., \& RaAijmakers, J. G. W. (1999) Priming in a free association task as a function of association directionality. Memory \& Cognition, 27, 956-961.

\section{NOTES}

1. The precuing procedure that we have used with infants was originally described by Gulya, Rovee-Collier, Galluccio, and Wilk (1998) in a study of serial learning by 3- and 6-month-olds. In the testing of infants' retention of the serial list, it has been necessary to precue earlier items in the list in order for the infants to recognize items later on the list. Gulya, Sweeney, and Rovee-Collier (1999) subsequently found it necessary to use a precue $24 \mathrm{~h}$ after a reactivation treatment as well. In using the train and puppet tasks, the different relative retention functions of the two tasks meant that initial retrieval of the train memory was necessary to retrieve the puppet memory after delays longer than 1 day (Barr et al., 2001). During pilot testing, we confirmed that after reactivation, precuing was necessary before the puppet test as well. That is, $24 \mathrm{~h}$ after the reactivation treatment, the train memory still had to be retrieved first in order for the memory of the puppet task to be retrieved. Because we did not know whether an effective precue for the puppet imitation memory required that infants actually see the train in motion or not, we used two different precues-one in which the infants saw the moving train for 2 min (a procedure identical to the priming procedure that they had experienced $24 \mathrm{~h}$ earlier) and one in which the infants saw the nonmoving train for $2 \mathrm{~min}$. The latter condition also served as a long-term retention test for the infants' memory of the train task; the infants who were precued with the moving train were tested for retention of the train task immediately after the puppet imitation test. (For the infants who had remembered the puppet task, the train test was superfluous.)

2. Although the train memory must be retrieved in order for the puppet memory to be retrieved, pilot testing revealed that the reverse is not the case. The puppet precue was included in Experiment 2 simply to ensure that the infants remained in the experimental situation for the same amount of time as those in Experiment 1 before their critical retention test.

(Manuscript received March 16, 2001; revision accepted for publication November 13, 2001.) 